\title{
Francois-Antoine Chevrier. Mémoires d'une honnête femme écrits par elle-même et publiés par M. de Chevrier
}

\section{Franco Piva}

\section{Q OpenEdition}

\section{Edizione digitale}

URL: https://journals.openedition.org/studifrancesi/26398

DOI: 10.4000/studifrancesi.26398

ISSN: 2421-5856

\section{Editore}

Rosenberg \& Sellier

\section{Edizione cartacea}

Data di pubblicazione: 1 avril 2007

Paginazione: 185

ISSN: 0039-2944

\section{Notizia bibliografica digitale}

Franco Piva, «Francois-Antoine Chevrier. Mémoires d"une honnête femme écrits par elle-même et publiés par M. de Chevrier», Studi Francesi [Online], 151 (LI | I) | 2007, online dal 30 novembre 2015, consultato il 23 novembre 2021. URL: http://journals.openedition.org/studifrancesi/26398 ; DOI: https://doi.org/ 10.4000/studifrancesi.26398

Questo documento è stato generato automaticamente il 23 novembre 2021.

\section{(c) (1)}

Studi Francesi è distribuita con Licenza Creative Commons Attribuzione - Non commerciale - Non opere derivate 4.0 Internazionale. 


\title{
Francois-Antoine Chevrier. Mémoires d'une honnête femme écrits par elle- même et publiés par M. de Chevrier
}

\author{
Franco Piva
}

\section{NOTIZIA}

FRANCOIS-ANTOINE CHEVRIER. Mémoires d'une honnête femme écrits par elle-même et publiés par M. de Chevrier. Présentation et notes par Michèle воковZA-КАнАN, Publications de

l'Université de Saint-Étienne Jean Monnet, 2005 («Lire le Dix-huitième siècle»), pp. 195.

1 I Mémoires d'une honnête femme écrits par elle-même sono, di fatto, l'unico romanzo di un autore più noto per la sua produzione giornalistica e pamphlettistica; di un autore che, avendo deciso di seguire la vocazione letteraria, non seppe tuttavia uscire mai veramente dall'anonimato e che finì per collocarsi in quello sciame di scrittori costretti, per sopravvivere, ad operare nel sottobosco letterario dell'epoca: lo fece con una serie abbastanza nutrita di opere di vario genere tutte percorse da una innegabile, e per molti versi non spregevole vena satirica, esercitata soprattutto nei riguardi di quel mondo aristocratico e mondano di cui molti, già verso la metà del Settecento, avevano iniziato a denunciare la vacuità. Lo stesso atteggiamento animò Chevrier nella composizione dei Mémoires d'une honnête femme; con la differenza che, oltre che nei riguardi di una certa società, la dimensione parodica si è esercitata anche sul genere stesso del romanzo. I riferimenti ad alcune delle opere narrative più note dell'epoca sono numerose ed il più delle volte espliciti: dal titolo, che richiama quello dei Mémoires d'un honnête homme di Prévost, all'incipit del romanzo che fa eco a quello della Vie de Marianne di Marivaux, per proseguire con tutta una serie di episodi e di topoi che rinviano ad altre celebri opere dell'epoca: dagli Egarements du coeur et de l'esprit di Crébillon alle Confessions du comte de ${ }^{* * *}$ di Duclos, per non citare che le più note. I Mémoires d'une honnête femme di Chevrier possono essere considerati un'opera per molti versi esemplare di un certo tipo di romanzo settecentesco: a metà strada tra 
l'imitazione di quei grandi modelli che avevano fatto del romanzo un genere finalmente degno di attenzione, e in fondo anche di rispetto, e, d'altra parte, la presa di distanza, più o meno cosciente, da un genere che, pur presentandosi nelle vesti della più autentica confessione, denunciava, al tempo stesso, la vacuità delle sue pretese con il ripetersi degli stessi temi e degli stessi procedimenti. «Sans offrir une méditation approfondie des thèmes principaux d'un imaginaire romanesque collectif, - scrive Michèle Bokobza-Kahan nella sua bella ed acuta Introduction - Chevrier en reprend néanmoins les constantes: les vices à la mode et les infortunes de la vertu, la tyrannie de l'homme et la subordination de la femme, la vie mondaine parisienne et ses avatars provinciaux. Il ne se préoccupe ni de la vérité psychologique des personnages, ni de la vraisemblance des situations romanesques, ni du réalisme pictural. Le roman tire son intérêt de la manière dont la récupération de références connues et la reprise de certaines formes conventionnelles appréciées à l'époque permettent à l'auteur de mieux s'en démarquer. En simplifiant à l'extrême les structures narratives du roman libertin, d'une part, et en gonflant jusqu'à l'absurde les topoï propres du roman sentimental, d'autre part, Chevrier cherche moins à divertir en caricaturant des personnages et des situations déjà connus qu'à mettre à nu certains procédés romanesques pour mieux souligner les vices et les ridicules de la société mondaine, la simplification extrême des motivations psychologiques qui déterminent la conduite des personnages et enfin les nombreux clichés dans le langage qui constituent les éléments principaux de la parodie de Chevrier. Mais les enjeux ludiques traditionnellement conférés au genre parodique sont largement dépassés par une problématique des rapports de l'homme avec son environnement social aliénant. De plus la question de la vertu féminine y est traitée de manière plus complexe qu'à l'ordinaire car il ne s'agit pas tant de la dénigrer que d'en représenter des compromissions réductrices qui finissent par la vider de son sens profond». Non si potrebbero, a nostro avviso, definire meglio i limiti ma anche i pregi di un'opera che meritava di essere tratta dall'oblio in cui era caduta dopo il notevole successo (cinque edizioni dal 1753 al 1774) incontrato negli anni che seguirono la sua prima pubblicazione. 